\title{
A REALIZAÇÃO DA DEMOCRACIA ATRAVÉS DA PARTICIPAÇÃO NAS POLÍTICAS PÚBLICAS: A AFIRMAÇÃO DEMOCRÁTICA DO PROGRAMA NACIONAL DE DIREITO HUMANOS (PNDH-3)
}

\author{
Jeferson Dytz Marin ${ }^{*}$ \\ Marina Bertarello**
}

\begin{abstract}
Sumário I - A Participação Democrática nas Políticas Públicas: a garantia de acesso às decisões públicas II - Ações Programáticas do PNDH-3 para a garantia de participação e controle social das políticas públicas em Direitos Humanos: a concretude da participação democrática Considerações Finais Referências Bibliográficas
\end{abstract}

- Resumo: A democracia representa, justamente, o fato de que cada cidadão tem um poder de decisão acerca das políticas públicas, um poder de ação na esfera pública. É preciso reconhecer que todos têm o direito de participar na vida democrática do país e, especialmente, as decisões acerca das políticas públicas devem ser tomadas de forma tão aberta e tão próxima do cidadão quanto possível, concretizando a participação como elemento fundamental da democracia. Por isso, o Programa Nacional de Direitos Humanos (PNDH-3) representa um instrumento na afirmação democrática dos Direitos Humanos, haja vista possibilitar uma interação democrática com a sociedade civil, a fim de assegurar a participação e o controle social das políticas públicas em Direitos Humanos.

- Palavras-chave: Democracia; Políticas Públicas; Participação; Programa Nacional de Direitos Humanos (PNDH-3).

- Abstract: Democracy is precisely the fact that every citizen has a power to take decisions about public policy, a power to act in the public sphere. Recognize that everyone has the right to participate in the democratic life of the country, and especially the decisions about public policy should be taken as openly and as closely as possible to the citizen, fulfilling participation as a fundamental element of democracy. Therefore, the National Program for Human Rights (PNDH-3) represents a tool in the democratic affirmation of human rights, considering a possible interaction with democratic civil society in order to ensure participation and social control of public policies on Human Rights .

- Keywords: Democracy; Public Policy; Participation; National Program for Human Rights (PNDH-3).

\section{Introdução}

É evidente que a melhor forma de governo é aquela na qual todo homem, seja ele quem for, pode agir da melhor maneira e viver feliz.

Aristóteles $^{1}$

\footnotetext{
"Advogado. Professor da Universidade de Caxias do Sul - UCS. Doutorando em Direito - UNISINOS (RS). Mestre em Direito - UNISC (RS). Membro da Academia Brasileira de Direito Processual. Autor da série Jurisdição e Processo, pela Editora Juruá, de Curitiba. E-mail: jmarin271@hotmail.com ** Advogada. Mestranda em Direito Público pela Universidade do Vale do Rio dos Sinos (UNISINOS/ RS). Bolsista CAPES-PROSUP. E-mail: mari.ber@ibest.com.br
} ${ }^{1}$ ARISTÓTELES. Política. Traduzido por Pedro Constantin Tolens. 5.ed. São Paulo: Martin Claret, 2010, p. 236. 
A democracia necessita da participação para se efetivar, uma vez que o próprio princípio democrático implica participação nos processos de decisão, pois não há como se negar que a democracia desloca o poder para o povo, sendo que o cidadão tem o direito de participar ativamente das decisões acerca das políticas públicas, sob pena de estar-se difundindo uma democracia meramente retórica.

A relação entre os Direitos Humanos e a participação democrática é constitutiva, pois a fruição dos Direitos Humanos não ocorre fora da participação democrática, independentemente do fato de estarem consagrados na Constituição Federal, sem a ação no espaço público não há efetividade dos Direitos Humanos, mas sim mera declaração em textos legais.

A afirmação democrática dos Direitos Humanos é fundamental para o respectivo gozo, por isso o Decreto $\mathrm{n}^{\circ} 7.037$, de 21 de dezembro de 2009, que institui o terceiro Programa Nacional de Direitos Humanos, tendo como discurso o reafirmar da democracia impulsionado pelos Direitos Humanos, através da interação democrática com a sociedade civil e da garantia da participação e do controle social das políticas públicas em Direitos Humanos, contribui para a afirmação democrática.

\section{I - A Participação Democrática nas Políticas Públicas: a garantia de acesso às decisões públicas}

A palavra democracia deriva do grego demos (povo) e kratos (poder), o que significa identificar a democracia como o poder do povo, tanto é assim que "para os antigos, o vocábulo democracia significa o poder do démos e não como se observa atualmente o poder dos representantes do démos" ${ }^{2}$, ou seja, a democracia representa um poder que emana do povo, não um poder inerte, mas um poder ativo exercido pelo povo.

Por isso, "a democracia define-se, não como a criação política da sociedade, mas como a penetração do maior número de atores sociais individuais e coletivos, no campo das decisões" ${ }^{3}$, já que tão somente os mecanismos democráticos representativos não definem a democracia como o poder do povo, mas apenas refletem o poder dos representantes do povo, sendo necessária a participação democrática para a construção de uma democracia efetivamente emanada do povo.

Nesse sentido, J. J. Rousseau, em Do Contrato Social ressalta que o pacto social estabelecido entre os cidadãos tem igualdade, ou seja, todos os cidadãos devem gozar dos mesmos direitos, incluindo o direito de participar do processo de tomada de decisão no âmbito público e, por isso, todo ato de soberania (incluindo a soberania popular) é ato de todos os cidadãos, nota-se:

Por qualquer ângulo que se remonte ao princípio, chega-se sempre, à mesma conclusão: saber que o pacto social estabelecido entre os cidadãos tem tal igualdade, que eles se encontram todos nas mesmas condições, e todos devem gozar dos

${ }^{2}$ AIETA, Vânia Siciliano. Democracia. In: BARRETO, Vicente de Paulo (Coord.).

Dicionário de Filosofia do Direito. Rio de Janeiro: Renovar, 2006, p. 191.

${ }^{3}$ TOURAINE, Alain. O que é democracia?. Petrópolis: Vozes, 1996, p. 41-42. 
mesmos direitos. Assim, pela natureza do pacto, todo ato de soberania, isto é, todo ato autêntico da vontade geral, obriga ou favorece igualmente todos os cidadãos, de modo que o soberano conhece somente o corpo da nação e não distingue nenhum dos que a compõe. ${ }^{4}$

Então, para Rousseau, o que é propriamente um ato de soberania?

\begin{abstract}
Não é uma convenção do superior com o inferior, mas uma convenção do corpo com cada um de seus membros: convenção legítima, porque tem por base o contrato social, equitativo, porque é comum a todos, útil, porque não pode ter outro objeto senão o bem geral, e sólido porque tem como garantia a força pública e o poder supremo. Enquanto os súditos não estão submetidos senão a tais convenções, eles não obedecem a ninguém, mas apenas à própria vontade; e perguntar até onde se estendem os respectivos direitos do soberano e dos cidadãos é perguntar até que ponto eles podem engajar-se consigo mesmos, cada um para todos e todos para cada um. ${ }^{5}$
\end{abstract}

Assim, Rousseau sintetiza de forma objetiva a expressão da soberania popular - basilar da democracia - como um ato comum a todos os cidadãos, um ato de engajamento de cada um para todos e de todos para cada um, pelo que não existe ato de soberania isolado, imposto, vertical, distante da participação democrática, mas o que legitima o ato soberano é, acima de tudo, a participação e a autoridade horizontal de todos para todos, já que o próprio pacto social coloca os cidadãos na igualdade e, aqui, especificamente, da igualdade do cidadão de participar do processo de tomada de decisão nas políticas públicas.

"Na democracia, os cidadãos, embora coletivamente soberanos, também são, como indivíduos, participantes das contendas que julgam coletivamente. A equidade entre os cidadãos exige que participem como iguais"6. Democracia sem participação do cidadão no processo de tomada de decisões públicas não é democracia, já mencionava Aristóteles que "aquele que tem o poder de tomar parte na administração deliberativa ou judicial de alguma Cidade, dizemos que é cidadão daquela Cidade"7 ou, pode-se dizer, o exercício democrático da cidadania perpassa pela participação ativa do cidadão no espaço público.

A própria democracia necessita da participação para se efetivar, pois o princípio democrático implica participação nos processos de decisão, haja vista que "a participação do cidadão no poder, como característica da democracia, configura-

${ }^{4}$ ROUSSEAU, Jean-Jacques. Do Contrato Social: princípios de direito político. Traduzido por J. Cretella Jr. e Agnes Cretella. 2.ed. São Paulo: Revista dos Tribunais, 2008, p. 51.

${ }^{5}$ Idem, ibidem.

${ }^{6}$ DWORKIN, Ronald. A Virtude Soberana: a teoria e a prática da igualdade. Traduzido por Jussara Simões. São Paulo: Martins Fontes, 2005, p. 511.

${ }^{7}$ ARISTÓTELES. Política. Traduzido por Pedro Constantin Tolens. 5.ed. São Paulo: Martin Claret, 2010, p. 115.

${ }^{8}$ BARACHO, José Alfredo de Oliveira. Teoria Geral da Cidadania: a plenitude da cidadania e as garantias constitucionais e processuais. São Paulo: Saraiva, 1995, p.03. 
se pela tomada de posição concreta na gestão dos negócios da cidade, isto é, no poder" ${ }^{8}$, enfim a democracia desloca o poder para o povo, sendo que o cidadão tem o direito (e o dever) de participar ativamente das decisões políticas, sob pena de estar-se propagando uma democracia meramente retórica.

A democracia é, justamente, o fato de que cada cidadão tem um poder de decisão acerca das políticas públicas, um poder de ação na esfera pública. Hannah Arendt descreve a ação como requisito da condição humana, pois "quem quer que vivesse unicamente uma vida privada - o homem que, como o escravo, não podia participar da esfera pública ou que, como o bárbaro, não se desse ao trabalho de estabelecer tal esfera - não era inteiramente humano" ${ }^{\prime \prime}$, pelo que a ação no espaço público é condição de possibilidade da democracia.

E o espaço público representa o locus de efetivação da democracia, de uma democracia que não se enraíza apenas na representação política, mas que faz do espaço público o lugar da participação. Acerca do conceito de espaço público, leciona Bonavides:

\begin{abstract}
Encerra o conceito de espaço público, a nosso ver, as virtualidades do processo democrático mais aberto, intenso e profundo a que se possa aspirar, enraizado na consciência e na ação dos que, com a expansão da imaginação criativa, introduziram instrumentos novos com que elidir a supremacia da intermediação clássica - a da chamada representação política cuja crise é manifesta e cuja decadência é irremediável. ${ }^{10}$
\end{abstract}

A ação na esfera pública ou, em outras palavras, a participação na decisão acerca das políticas públicas é condição primeira da existência da sociedade democrática, para que a imagem do povo-Uno se concretize, o que não ocorre na democracia que elide a participação cidadã nas políticas públicas, pois democracia sem acesso às decisões não é verdadeiramente democracia, mas sim um pseudo regime democrático similar ao totalitarismo, em que a decisão é verticalizada e imposta.

Claude Lefort, em $A$ Invenção Democrática, ressalta que a democracia resgata a imagem da sociedade como tal, sociedade puramente humana, a imagem do povo-Uno, nota-se:

O que advém com a democracia é a imagem da sociedade como tal, sociedade puramente humana, mas simultaneamente sociedade sui generis cuja natureza própria requer um conhecimento objetivo; é, em decorrência da destruição do núcleo monárquico de legitimidade e da destruição da arquitetura dos corpos, a imagem de um espaço homogêneo de direito, ofere-

\footnotetext{
${ }_{9}^{9}$ ARENDT, Hannah. A Condição Humana. Traduzido por Roberto Raposo. Rio de Janeiro, Forense, 1987, p. 48.

${ }^{10}$ BONAVIDES, Paulo. Teoria Constitucional da Democracia Participativa: por um Direito Constitucional de luta e resistência por uma Nova Hermenêutica por uma repolitização da legitimidade. 2.ed. São Paulo: Malheiros, 2003, p. 278.
} 
cido ao ponto de sobrevôo do saber e do poder; é a imagem do Estado, onisciente, onipotente, de um Estado ao mesmo tempo anônimo e, segundo o termo de Tocqueville, tutelar; é ainda, pelo fato de que a desigualdade se exerce nas fronteiras da igualdade das condições, a imagem de uma massa detentora do juízo último sobre o bem e o mal, o verdadeiro e o falso, o normal e o anormal, a imagem da opinião soberana; enfim, o que emerge é a imagem do povo a qual, eu observava, permanece indeterminada, mas de que é preciso não menos reconhecer que é suscetível de se determinar, de se atualizar fantasmaticamente como imagem do povo-Uno. ${ }^{11}$

Uma democracia exercida apenas nas eleições torna o povo alienado e inerte, pois inebriado na névoa de que a representatividade do demos é suficiente para guiar as decisões das políticas públicas, sendo desnecessária a participação após o pleito eleitoral. Na defesa da democracia ativa além dos limites da eleição, Giovanni Sartori sustenta que "a participação eleitoral não é participação real" ${ }^{12}$, pois o sentido de participação democrática é outro, como se depreende das seguintes palavras:

Própria e significativamente entendida, participação é um tomar parte pessoalmente, e um tomar parte desejado, auto-ativado. Ou seja, participação não é um simples 'fazer parte de' (um simples envolvimento em alguma ocorrência), e menos ainda um 'tornado parte de' involuntário. Participação é movimento próprio e, assim, o exato inverso de ser posto em movimento (por outra vontade), isto é, o oposto de mobilização. ${ }^{13}$

Na verdade, o kratos (poder) da democracia advém do povo, da soberania popular, como salienta Friedrich Müller o "kratein significa aqui em grau hierárquico igual: ser efetivamente levado a sério como o fato determinante, como o fator decisivo com vistas à legitimação. Quem deve nesse sentido ser efetivamente levado a sério como fator determinante? O povo" ${ }^{14}$, o que significa dizer que o povo deve participar ativamente na tomada de decisão das políticas públicas, sob pena de aniquilar a democracia enquanto locus do poder emanado do povo para o povo.

O constitucionalista Paulo Bonavides ressalta que a democracia é mais do que forma de governo, é direito do povo de reger-se pela sua própria vontade, notase:

Tanto quanto o desenvolvimento, é a democracia, por igual,

\footnotetext{
${ }^{11}$ LEFORT, Claude. A Invenção Democrática: os limites do totalitarismo. Traduzido por Isabel Marva Loureiro. Brasília: Brasiliense, 1983, p. 119.

${ }^{12}$ SARTORI, Giovanni. A Teoria da Democracia Revisitada: o debate contemporâneo. Traduzido por Dinah de Abreu Azevedo. São Paulo: Ática, 1994, p. 158.

${ }^{13}$ SARTORI, Giovanni. A Teoria da Democracia Revisitada: o debate contemporâneo. Traduzido por Dinah de Abreu Azevedo. São Paulo: Ática, 1994, p. 159.

${ }^{14}$ MÜLLER, Friedrich. Quem é o Povo? A questão fundamental da democracia. Traduzido por Peter Naumann. 2.ed. São Paulo: Max Limonad, 2000, p. 111.
} 
direito do povo; direito de reger-se pela sua própria vontade; e, mais do que forma de governo, se converte sobretudo em pretensão da cidadania à titularidade direta e imediata do poder, subjetivado juridicamente na consciência social e efetivado, de forma concreta, pelo cidadão, em nome e em proveito da Sociedade, e não do Estado propriamente dito - quer o Estado liberal que separa os poderes, quer o Estado social, que monopoliza competências, atribuições e prerrogativas..$^{15}$

"Democratizar a democracia através da participação significa, em termos gerais, intensificar a otimização da participação direta e ativa de homens e mulheres no processo de decisão" ${ }^{16}$, por isso a participação democrática nas políticas públicas não representa mera retórica da democracia participativa, mas sim denota a concretude da própria democracia que necessita para se efetivar da participação ativa dos cidadãos no processo de decisão e não apenas no momento do exercício do sufrágio.

Boaventura de Sousa Santos também compartilha do entendimento de que "a renovação da teoria democrática assenta, antes de mais, na formulação de critérios democráticos de participação política que não confinem esta ao ato de votar"17, uma vez que não se pode olvidar que a democracia é a garantia de acesso às decisões públicas, especialmente no processo de tomada de decisão tangente às políticas públicas que refletem diretamente no povo, legítimo detentor do poder que deve ser levado a sério como fator determinante da decisão no espaço público.

$E$ a renovação da teoria democrática é essencial para que seja viabilizado o exercício da democracia em terrae brasilis, pois como afirma Sérgio Buarque de Holanda a democracia foi importada e aplicada conforme os interesses privados das classes dominantes, eis:

\footnotetext{
A democracia no Brasil foi sempre um lamentável mal-entendido. Uma aristocracia rural e semifeudal importou-a e tratou de acomodá-la, onde fosse possível, aos seus direitos ou privilégios, os mesmos privilégios que tinham sido no Velho Mundo, o alvo da luta da burguesia contra os aristocratas. E assim puderam incorporar à situação tradicional, ao menos como fachada ou decoração externa, alguns lemas que pareciam os mais acertados para a época e eram exaltados nos livros e discursos. ${ }^{18}$
}

\footnotetext{
${ }^{15}$ BONAVIDES, Paulo. Teoria Constitucional da Democracia Participativa

: por um Direito Constitucional de luta e resistência por uma Nova Hermenêutica por uma repolitização da legitimidade. 2.ed. São Paulo: Malheiros, 2003, p. 161.

${ }^{16}$ CANOTILHO, José Joaquim Gomes. Direito Constitucional e Teoria da Constituição. Coimbra: Almedina, 1998, p. 301.

${ }^{17}$ SANTOS, Boaventura de Sousa. Pela Mão de Alice: o social e o político na pós-modernidade. 5.ed. São Paulo: Cortez, 1999, p. 270.

${ }^{18}$ HOLANDA, Sérgio Buarque de. Raízes do Brasil. 26.ed. São Paulo: Companhia das Letras, 1995, p. 160.
} 
A reforma democrática ou, melhor dizendo, a renovação da democracia é necessária, pois "a experiência já tem demonstrado largamente como a pura e simples substituição dos detentores do poder público é um remédio aleatório, quando não precedida e até certo ponto determinada por transformações complexas e verdadeiramente estruturais na vida da sociedade" ${ }^{19}$, a fim de que o cidadão exerça a democracia como deve ser exercida, através do acesso às decisões públicas.

Não se está querendo dizer que a democracia representativa deve ser derrocada, mas sim que a participação no acesso às decisões públicas deve ser introduzida na democracia, porque apenas a manutenção da anacrônica democracia representativa que, em breves linhas, "significa genericamente que as deliberações coletivas, isto é, as deliberações que dizem respeito à coletividade inteira, são tomadas não diretamente por aqueles que dela fazem parte, mas por pessoas eleitas para esta finalidade" 20 não será capaz de garantir o exercício da democracia que depende, indubitavelmente, da participação ativa nas políticas públicas.

"Isto implica que, de fato, democracia representativa e democracia direta não são dois sistema alternativos (no sentido de que onde existe uma não pode existir a outra), mas são dois sistemas que se podem integrar reciprocamente" ${ }^{21}$, pelo que é possível inferir a necessidade de redemocratizar a democracia, não extirpar a democracia representativa, mas sim integrá-la com o elemento da participação no processo de tomada de decisão no espaço público, isto é, democratizando-a.

É preciso reconhecer que a democracia representativa não fornece todas as condições necessárias à concretização da democracia, pois todos têm o direito de participar na vida democrática do país e, especialmente, as decisões acerca das políticas públicas devem ser tomadas de forma tão aberta e tão próxima do cidadão quanto possível, assegurando assim a máxima presença do povo no poder e, por consectário, implementando a participação como elemento fundamental da democracia.

\section{II - Ações Programáticas do PNDH-3 para a garantia de participação e controle social das políticas públicas em Direitos Humanos: a concretude da participação democrática}

O Decreto $\mathrm{n}^{0} 7.037$, de 21 de dezembro de 2009, institui em solo brasileiro o terceiro Programa Nacional de Direitos Humanos - PNDH-3, tendo como discurso de abertura a reafirmação de que "o Brasil fez uma opção definitiva pelo fortalecimento da democracia, não apenas a democracia política e institucional, grande anseio popular que a Constituição de 1988 já materializou, mas democracia também no

\footnotetext{
${ }^{19}$ Idem, p. 178.

${ }^{20}$ BOBBIO, Norberto. O Futuro da Democracia. Traduzido por Marco Aurélio Nogueira. 11.ed. São Paulo: Paz e Terra, 2009, p. 56.

${ }^{21}$ BOBBIO, Norberto. O Futuro da Democracia. Traduzido por Marco Aurélio Nogueira. 11.ed. São Paulo: Paz e Terra, 2009, p. 65.

${ }^{22}$ BRASIL. SECRETARIA ESPECIAL DOS DIREITOS HUMANOS DA PRESIDÊNCIA DA REPÚBLICA. Programa Nacional de Direitos Humanos (PNDH-3). Brasília: SEDH/PR, 2010, p.11.
} 
que diz respeito à igualdade econômica e social"22, ou seja, o Programa visa, sobretudo, o reafirmar da democracia impulsionado pelos Direitos Humanos, que carregam a bandeira democrática.

É sob o impulso dinâmico desses movimentos que os Direitos Humanos se fortalecem, erguendo como bandeira a democratização permanente do Estado e da própria sociedade. É deles, também, que o Estado vem colhendo crescentemente demandas e exigências para incorporá-las a sua ação programática nas diferentes políticas públicas. O reconhecimento e a incorporação dos Direitos Humanos no ordenamento social, político e jurídico brasileiro resultam de um processo de conquistas históricas, que se materializaram na Constituição de $1988 .{ }^{23}$

Em que pese o fato de que "a vigência dos direitos independe de sua declaração em constituições, leis e tratados internacionais, exatamente porque se está diante de exigências de respeito à dignidade humana, exercidas contra todos os poderes estabelecidos, oficiais ou não"24, não há como negar o papel inaugural e imprescindível da Declaração Universal dos Direitos Humanos, de 10 de dezembro de 1948, que fundou os alicerces de uma sociedade democrática que tem o dever de proteger os Direitos Humanos, tanto é assim que o artigo XXIV, alínea "2", da Declaração, estabelece o princípio democrático, nota-se: "No exercício de seus direitos e liberdades, toda pessoa estará sujeita apenas às limitações determinadas pela lei, exclusivamente com o fim de assegurar o devido reconhecimento e respeito dos direitos e liberdades de outrem e de satisfazer às justas exigências da moral, da ordem pública e do bem-estar de uma sociedade democrática".

No Brasil, a Constituição Federal de 1988 foi propulsora da concretização democrática e, concomitantemente, concedeu aos Direitos Humanos papel de destaque, tanto que obriga o país a reger suas relações internacionais com prevalência dos Direitos Humanos. Todavia, as diretrizes nacionais que orientam a atuação do poder público no âmbito dos Direitos Humanos foram desenvolvidas a partir de 1996, ano de lançamento do primeiro Programa Nacional de Direitos Humanos - PNDH I. Passados mais de dez anos do fim da ditadura, as demandas sociais da época se cristalizaram com maior ênfase na garantia dos direitos civis e políticos. O Programa foi revisado e atualizado em 2002, sendo ampliado com a incorporação dos direitos econômicos, sociais e culturais, o que resultou na publicação do segundo Programa Nacional de Direitos Humanos - PNDH II. ${ }^{25}$

A terceira versão do Programa Nacional de Direitos Humanos - PNDH-3 representa mais um passo na afirmação democrática dos Direitos Humanos, através de uma interação democrática com a sociedade civil e da garantia da participação e do controle social nas políticas públicas em Direitos Humanos, o que resta evidente

\footnotetext{
${ }^{23}$ Idem, p.15.

${ }^{24}$ COMPARATO, Fábio Konder. A Afirmação Histórica dos Direitos Humanos.5.ed. São Paulo: Saraiva, 2007, p. 227.

${ }^{25}$ BRASIL. SECRETARIA ESPECIAL DOS DIREITOS HUMANOS DA PRESIDÊNCIA DA REPÚBLICA. Programa Nacional de Direitos Humanos (PNDH-3). Brasília: SEDH/PR, 2010, p.16.
} 
no Eixo Orientador I, "Interação Democrática entre Estado e Sociedade", com a Diretriz 1 - "Interação democrática entre Estado e sociedade civil como instrumento de fortalecimento da democracia participativa" e com o Objetivo Estratégico I, sob o título "Garantia da participação e do controle social das políticas públicas em Direitos Humanos, um diálogo plural e transversal entre os vários atores sociais".

Nesse novo cenário, o diálogo entre Estado e sociedade civil assumiu especial relevo, com a compreensão e a preservação do distinto papel de cada um dos segmentos no processo de gestão. A interação é desenhada por acordos e dissensos, debates de ideias e pela deliberação em torno de propostas. Esses requisitos são imprescindíveis ao pleno exercício da democracia, cabendo à sociedade civil exigir, pressionar, cobrar, criticar, propor e fiscalizar as ações do Estado. Por isso, uma das finalidades básicas do Programa Nacional de Direitos Humanos (PNDH-3) é dar continuidade à integração e ao aprimoramento dos mecanismos de participação existentes, bem como criar novos meios de construção e monitoramento das políticas públicas sobre Direitos Humanos no Brasil. ${ }^{26}$

Aperfeiçoar a interlocução entre Estado e sociedade civil depende da implementação de medidas que garantam à sociedade maior participação no acompanhamento e monitoramento das políticas públicas em Direitos Humanos, num diálogo plural e transversal entre os vários atores sociais e deles com o Estado. Fortalecer as informações em Direitos Humanos com produção e seleção de indicadores para mensurar demandas, monitorar, avaliar, reformular e propor ações efetivas garante e consolida o controle social e a transparência das ações governamentais ${ }^{27}$, ou seja, o Programa Nacional de Direitos Humanos - PNDH-3 visa instituir a participação democrática no processo de tomada de decisão acerca das políticas públicas em Direitos Humanos.

Nesse sentido, para concretizar a participação democrática e o controle social das políticas públicas, o Objetivo Estratégico I - Garantia da participação e do controle social das políticas públicas em Direitos Humanos, um diálogo plural e transversal entre os vários atores sociais, prevê as seguintes ações programáticas:

a) Apoiar, junto ao Poder Legislativo, a instituição do Conselho
Nacional dos Direitos Humanos, dotado de recursos humanos,
materiais e orçamentários para o seu pleno funcionamento, e
efetuar seu credenciamento junto ao Escritório do Alto
Comissariado das Nações Unidas para os Direitos Humanos
como "Instituição Nacional Brasileira", como primeiro passo
rumo à adoção plena dos "Princípios de Paris".
b) Fomentar a criação e o fortalecimento dos conselhos de Direi-
tos Humanos em todos os estados e municípios e no Distrito
Federal, bem como a criação de programas estaduais de Direitos

${ }^{26}$ BRASIL. SECRETARIA ESPECIAL DOS DIREITOS HUMANOS DA PRESIDÊNCIA DA REPÚBLICA. Programa Nacional de Direitos Humanos (PNDH-3). Brasília: SEDH/PR, 2010, p. 22.

${ }^{27}$ Idem, p.23. 


\begin{abstract}
Humanos.
c) Criar mecanismos que permitam ação coordenada entre os diversos conselhos de direitos, nas três esferas da Federação, visando a criação de agenda comum para a implementação de políticas públicas de Direitos Humanos.

d) Criar base de dados dos conselhos nacionais, estaduais, distrital e municipais, garantindo seu acesso ao público em geral.

e) Apoiar fóruns, redes e ações da sociedade civil que fazem acompanhamento, controle social e monitoramento das políticas públicas de Direitos Humanos.

f) Estimular o debate sobre a regulamentação e efetividade dos instrumentos de participação social e consulta popular, tais como lei de iniciativa popular, referendo, veto popular e plebiscito.

g) Assegurar a realização periódica de conferências de Direitos Humanos, fortalecendo a interação entre sociedade civil e poder público. ${ }^{28}$
\end{abstract}

O Objetivo Estratégico I do Eixo Orientador I do Programa Nacional de Direitos Humanos - PNDH-3 representa uma tentativa de instaurar uma democracia ativa, pois "democracia somente pode subsistir, isto é, continuar viva, como democratização em ampliação permanente" ${ }^{29}$, pressupondo assim que o regime democrático depende da participação popular, da ação do povo na esfera pública e, especialmente, nas políticas públicas de Direitos Humanos, instaurando-se fóruns da sociedade civil que realizem o controle social e monitoramento, estimulando o debate e a regulamentação de instrumentos de participação e consulta popular, enaltecendo a democracia por meio da interação da sociedade nas decisões acerca das políticas públicas.

"Os direitos humanos não são mais simplesmente solenes declarações de intenção, mas, muito antes, uma parte obrigatória da ordem do direito e do Estado" ${ }^{30}$, por isso o Programa Nacional de Direitos Humanos (PNDH-3) inseriu em suas diretrizes a participação democrática nas políticas públicas de Direitos Humanos, haja vista a constatação inegável de que "os direitos democráticos de co-participação fazem parte dos direitos humanos" ${ }^{31}$, ou seja, a participação democrática é elemento fundamental para a democracia e integra os direitos humanos.

A própria construção dos Direitos Humanos advém da participação

\footnotetext{
${ }^{28}$ BRASIL. SECRETARIA ESPECIAL DOS DIREITOS HUMANOS DA PRESIDÊNCIA DA REPÚBLICA. Programa Nacional de Direitos Humanos (PNDH-3). Brasília: SEDH/PR, 2010, p. 24-25.

${ }^{29}$ MÜLLER, Friedrich. Que grau de exclusão social ainda pode ser tolerado por um sistema democrático?. In: PIOVESAN, Flávia (Coord.). Direitos Humanos, Globalização Econômica e Integração Regional: desafios do Direito Constitucional Internacional. São Paulo: Max Limonad, 2002, p. 569.

${ }^{30}$ HÖFFE, Otfried. Justiça Política: fundamentação de uma filosofia crítica do Direito e do Estado. Traduzido por Ernildo Stein. Petrópolis: Vozes, 1991, p. 372.

${ }^{31}$ Idem, p. 369.
} 
democrática, pois como bem esclarece Viola, "os direitos humanos têm sido, ao longo da história, uma construção dos múltiplos movimentos sociais, e não o resultado de um ordenamento jurídico ou o efeito de uma declaração" ${ }^{32}$, não exsurgem de forma espontânea dos textos legais, mas necessitam da ação do povo na esfera pública para efetivação, sob pena de serem apenas uma abstração jurídica distante da práxis social.

A relação entre os direitos humanos e a participação democrática é constitutiva, no sentido de que os direitos humanos são considerados a espinha dorsal-jurídica da sociedade democrática, nota-se pela explicação de Barreto:

\begin{abstract}
Ora, quais seriam os valores mínimos que serviriam para o desenvolvimento da democracia participativa? Nada mais são do que uma espécie de direito fora da ordem positiva, suprapositivo, que tem no seu bojo componentes morais, sociais, políticos e até econômicos, que salvaguardam as condições essenciais mínimas, constitutivas da dignidade da pessoa humana. Esse entendimento dos direitos humanos, como valores substanciais e universais permite que se estabeleça a ligação, tantas vezes negada pelas diferentes formas de positivismo jurídico, entre a ordem moral, constituída por agentes livres e iguais, e a ordem jurídica própria da sociedade e do Estado. Com isto os direitos humanos adquirem o status de direitos morais, mas que perpassam os ordenamentos jurídicos nacionais e permite que sejam considerados como a espinha dorsal jurídico-institucional da sociedade democrática. ${ }^{33}$
\end{abstract}

Nesse sentido, não restam dúvidas que democracia e direitos humanos se fundem, pois a fruição dos Direitos Humanos não ocorre fora da participação democrática, independentemente do fato de os Direitos Humanos estarem consagrados na Constituição Federal, sem a ação no espaço público não há efetividade e gozo dos Direitos Humanos. "E de nada serve uma Constituição que não seja sentida, vivida e praticada pela população e pelas autoridades constituídas. Logo, o pleno gozo dos Direitos Humanos depende, no dia-a-dia, da capacidade de participação política" ${ }^{34}$ e, principalmente, de interação do povo nas decisões acerca das políticas públicas.

E não se pode negar que a interação democrática entre Estado e sociedade

\footnotetext{
${ }^{32}$ VIOLA, Solon Eduardo Annnes. Direitos humanos e democracia no Brasil. São Leopoldo: Unisinos, 2008, p.41.

${ }^{33}$ BARRETO, Vicente de Paulo. Direitos Humanos, Democracia e Globalização. In: BARRETO, Vicente de Paulo; CULLETON, Alfredo Santiago; STRECK, Lenio Luiz (Orgs.).

20 Anos de Constituição: os Direitos Humanos entre a Norma e a Política. São Leopoldo: Oikos, 2009, p. 262.

${ }^{34}$ PAGLIARINI, Alexandre Coutinho. Manifesto em Favor da Democracia (e dos Direitos Humanos) no Estado Nacional, na Comunidade Internacional e na Sociedade Civil. In: CLÈVE, Clèmerson Merlin; PAGLIARINI, Alexandre Coutinho; SARLET, Ingo Wolfgang. Direitos Humanos e Democracia. Rio de Janeiro: Forense, 2007, p. 135.
} 
civil consubstancia um instrumento de fortalecimento da democracia participativa, tão importante para a implementação da garantia de participação e controle social das políticas públicas em Direitos Humanos, já que viabiliza a ação no espaço público e torna o povo ator da política, participante ativo do processo de tomada de decisões políticas.

Nota-se pelas palavras de Höffe a importância da democracia participativa na consolidação do povo como ator político, pois com a sua ajuda, "o povo não se constitui simplesmente como eleitorado temporário, eventualmente acompanhado de constantes pesquisas de opinião política, mas como ator da política" ${ }^{35}$, o que figura elemento imprescindível para a concretização dos Direitos Humanos, posto que sem a participação democrática os Direitos Humanos não são gozados de forma concreta, mas tão somente residem na abstração advinda dos textos legais.

Boaventura de Sousa Santos, defensor da democracia participativa como instrumento de participação popular na tomada de decisões políticas, defende:

\begin{abstract}
Em primeiro lugar, a democracia participativa é importante porque proporciona a cada cidadão a oportunidade de participar na tomada de decisões políticas. A importância está no fato de esta forma de democracia permitir a expansão da cidadania e a inclusão daqueles que, de outra forma, seriam excluídos dos assuntos da comunidade ou da sociedade como um todo. $^{36}$
\end{abstract}

As políticas públicas de Direitos Humanos não devem apenas constar de diplomas legais advindos da democracia representativa, mas sim precisam florescer da participação democrática, materializando-se a época do fim dos direitos humanos, como enaltece Costas Douzinas:

\begin{abstract}
Na medida em que os direitos humanos começam a distanciar-se de seus propósitos dissidentes e revolucionários iniciais, na medida em que seu fim acaba obscurecido em meio a mais e mais declarações, tratados e almoços diplomáticos, podemos estar inaugurando a época do fim dos direitos humanos e do triunfo de uma humanidade monolítica. ${ }^{37}$
\end{abstract}

Os Direitos Humanos são imprescindíveis à sociedade democrática, eis que viabilizam a manifestação e discussão pública de problemas sociais e representam, concomitantemente, a expressão da parcela da população marginalizada, cuja voz,

\footnotetext{
${ }^{35}$ HÖFFE, Otfried. A Democracia no Mundo de Hoje. Traduzido por Tito Lívio Cruz Romão. São Paulo: Martins Fontes, 2005, p. 131.

${ }^{36}$ SANTOS, Boaventura de Sousa. Democratizar a democracia: os caminhos da democracia participativa. Rio de Janeiro: Civilização Brasileira, 2002, p. 156.

${ }^{37}$ DOUZINAS, Costas. OFim dos Direitos Humanos. Traduzido por Luzia Araújo. São Leopoldo: Unisinos, 2009, p. 384.
} 
muitas vezes, é calada, pelo que os Direitos Humanos fazem parte do espaço público democrático, nota-se:

\begin{abstract}
Os direitos humanos fazem parte do espaço público democrático, e não são apenas temas ou objeto de disputa política. Eles têm um caráter produtivo e positivo em relação às decisões coletivas, pois a participação ativa de atores coletivos que pretendem tornar efetivas as normas de enunciado universal provoca deslocamentos no debate público, uma vez que suas demandas interpelam os demais atores, que devem responder a elas. ${ }^{38}$
\end{abstract}

Por isso, o Programa Nacional de Direitos Humanos (PNDH-3) representa um instrumento da afirmação democrática dos Direitos Humanos, haja vista possibilitar uma interação democrática com a sociedade civil, a fim de assegurar a participação e o controle social das políticas públicas em Direitos Humanos, através de ações programáticas como a instauração de fóruns que estimulem o debate e a regulamentação de instrumentos de participação popular, bem como viabilizem a realização periódica de conferências de Direitos Humanos, fortalecendo a interação entre sociedade civil e poder público.

Assim, pode-se afirmar que o Programa Nacional de Direitos Humanos (PNDH-3), diante da inequívoca constatação de que os Direitos Humanos não são apena meras declarações formais de intenção e necessitam da participação do povo para a efetivação e gozo, inaugura ações programáticas tipicamente democráticas que garantem a participação do povo no espaço público por meio da interação da sociedade nas decisões acerca das políticas públicas de Direitos Humanos e, consequentemente, a participação democrática se consolida no processo de tomada de decisão, verdadeira finalidade da democracia.

\title{
Considerações Finais
}

Democracia sem participação do cidadão no processo de tomada de decisões acerca das políticas públicas não é democracia, mas sim um falso regime democrático fundamentado em decisões verticalizadas e impostas, sendo imprescindível o reconhecimento de que a democracia representativa não proporciona todas as condições necessárias à concretização da democracia, pois não assegura a participação democrática.

Sendo assim, o Programa Nacional de Direitos Humanos (PNDH-3) representa mais um passo na afirmação democrática do país, especialmente pelo fato de que viabiliza a interação democrática com a sociedade civil e a garantia da participação e do controle social das políticas públicas em Direitos Humanos, uma vez que a própria efetivação dos Direitos Humanos depende, inequivocamente, da ação do povo na esfera pública, da participação democrática, sob pena de constituírem mera

\footnotetext{
${ }^{38}$ KOERNER, Andrei. O Papel dos Direitos Humanos na Política Democrática: uma análise preliminar. Revista Brasileira de Ciências Sociais, v.18, n.53, p.143-181, out. 2003, p. 151-152.
} 
abstração jurídica.

Os Direitos Humanos são fundamentais à afirmação democrática, posto que possibilitam a discussão pública de problemas sociais, por isso o Programa Nacional de Direitos Humanos (PNDH-3) prevê ações programáticas democráticas que asseguram a participação popular nas políticas públicas em Direitos Humanos, reafirmando a democracia enquanto sinônimo de participação democrática e afirmando a efetividade dos Direitos Humanos.

\section{Referências Bibliográficas}

AIETA, Vânia Siciliano. Democracia. In: BARRETO, Vicente de Paulo (Coord.). Dicionário de Filosofia do Direito. Rio de Janeiro: Renovar, 2006.

BRASIL. SECRETARIA ESPECIAL DOS DIREITOS HUMANOS DA PRESIDÊNCIA DA REPÚBLICA. Programa Nacional de Direitos Humanos (PNDH-3). Brasília: SEDH/ PR, 2010.

ARENDT, Hannah. A Condição Humana. Traduzido por Roberto Raposo. Rio de Janeiro, Forense, 1987.

ARISTÓTELES. Política. Traduzido por Pedro Constantin Tolens. 5.ed. São Paulo: Martin Claret, 2010.

BARACHO, José Alfredo de Oliveira. Teoria Geral da Cidadania: a plenitude da cidadania e as garantias constitucionais e processuais. São Paulo: Saraiva, 1995.

BARRETO, Vicente de Paulo. Direitos Humanos, Democracia e Globalização. In: BARRETO, Vicente de Paulo; CULLETON, Alfredo Santiago; STRECK, Lenio Luiz (Orgs.). 20 Anos de Constituição: os Direitos Humanos entre a Norma e a Política. São Leopoldo: Oikos, 2009.

BOBBIO, Norberto. O Futuro da Democracia. Traduzido por Marco Aurélio Nogueira. 11.ed. São Paulo: Paz e Terra, 2009.

BONAVIDES, Paulo. Teoria Constitucional da Democracia Participativa: por um Direito Constitucional de luta e resistência por uma Nova Hermenêutica por uma repolitização da legitimidade. 2.ed. São Paulo: Malheiros, 2003.

COMPARATO, Fábio Konder. A Afirmação Histórica dos Direitos Humanos.5.ed. São Paulo: Saraiva, 2007.

CANOTILHO, José Joaquim Gomes. Direito Constitucional e Teoria da Constituição. Coimbra: Almedina, 1998.

DWORKIN, Ronald. A Virtude Soberana: a teoria e a prática da igualdade. Traduzido por Jussara Simões. São Paulo: Martins Fontes, 2005. 
DOUZINAS, Costas. O Fim dos Direitos Humanos. Traduzido por Luzia Araújo. São Leopoldo: Unisinos, 2009.

HÖFFE, Otfried. A Democracia no Mundo de Hoje. Traduzido por Tito Lívio Cruz Romão. São Paulo: Martins Fontes, 2005.

Justiça Política: fundamentação de uma filosofia crítica do Direito e do Estado. Traduzido por Ernildo Stein. Petrópolis: Vozes, 1991.

HOLANDA, Sérgio Buarque de. Raízes do Brasil. 26.ed. So Paulo: Companhia das Letras, 1995.

KOERNER, Andrei. O Papel dos Direitos Humanos na Política Democrática: uma análise preliminar. Revista Brasileira de Ciências Sociais, v.18, n.53, p.143-181, out. 2003.

LEFORT, Claude. A Invenção Democrática: os limites do totalitarismo. Traduzido por Isabel Marva Loureiro. Brasília: Brasiliense, 1983.

MÜLLER, Friedrich. Quem éo Povo? A questão fundamental da democracia. Traduzido por Peter Naumann. 2.ed. São Paulo: Max Limonad, 2000.

Que grau de exclusão social ainda pode ser tolerado por um sistema democrático?. In: PIOVESAN, Flávia (Coord.). Direitos Humanos, Globalização Econômica e Integração Regional: desafios do Direito Constitucional Internacional. São Paulo: Max Limonad, 2002.

PAGLIARINI, Alexandre Coutinho. Manifesto em Favor da Democracia (e dos Direitos Humanos) no Estado Nacional, na Comunidade Internacional e na Sociedade Civil. In: CLÈVE, Clèmerson Merlin; PAGLIARINI, Alexandre Coutinho; SARLET, Ingo Wolfgang. Direitos Humanos e Democracia. Rio de Janeiro: Forense, 2007.

ROUSSEAU, Jean-Jacques. Do Contrato Social: princípios de direito político. Traduzido por J. Cretella Jr. e Agnes Cretella. 2.ed. São Paulo: Revista dos Tribunais, 2008.

SANTOS, Boaventura de Sousa. Democratizar a democracia: os caminhos da democracia participativa. Rio de Janeiro: Civilização Brasileira, 2002.

Pela Mão de Alice: o social e o político na pós-modernidade. 5.ed. São Paulo: Cortez, 1999.

SARTORI, Giovanni. A Teoria da Democracia Revisitada: o debate contemporâneo. Traduzido por Dinah de Abreu Azevedo. São Paulo: Ática, 1994.

TOURAINE, Alain. O que é democracia?. Petrópolis: Vozes, 1996.

VIOLA, Solon Eduardo Annnes. Direitos humanos e democracia no Brasil. São Leopoldo: Unisinos, 2008. 
